\title{
1 . \\ Studies toward an indanone-based hybrid with potencial AchE inhibition to treat Alzheimer's disease
}

\author{
Talita Perez Cantuaria Chierrito ${ }^{1}$, Marcelo Rodrigues de Carvalho ${ }^{1}$, Ivone Carvalho ${ }^{1}$. \\ ${ }^{1}$ University of São Paulo, Faculty of Pharmaceutical Sciences of Ribeirão Preto \\ *tali@fcfrp.usp.br
}

Keywords: Alzheimer disease, acetylcholinesterase inhibitor, synthesis intermediate

\section{INTRODUCTION}

The Alzheimer's disease (AD) is a process that causes a progressive and irreversible decline of cognitive functions, which includes no organized behavior and psychotic symptoms. The progression of the disease symptoms is associated with structural changes in cholinergic synapses in certain brain regions and consequent impairment of cholinergic neurotransmission ${ }^{1,2}$.

The $A D$ is complex, and nowadays the therapeutic treatment offers only limited and few benefits for the patients, so it is essential to search for alternative $A D$ treatments. In this work, we summarize the synthesis of (4-piperidin-1-yl)-[(4-azidequinolin-2-yl)-methyl] methyl alcohol (8), as key intermediate to synthesize indanonebased hybrid (1) with potencial acetylcholinesterase inhibiton (Fig. 1) and to treat AD.

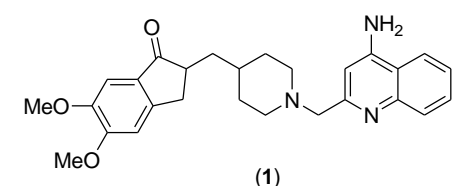

(1)

Figure 1. Indanone-based hybrid (1) as potencial inhibitor of acetylcholinesterase.

\section{RESULTS AND DISCUSSION}

As seen on scheme 1 (entry i), the treatment of antranilic acid (2) with $\mathrm{POCl}_{3}$ and acetone afforded the chloride-quinoline derivative (3) $\left(40 \%\right.$ yield) ${ }^{[3]}$. The methyl group of $\mathbf{3}$ was oxidized with $\mathrm{SeO}_{2}$ and TBHP (tert -butyl hidroperoxide) to give 4-chloropiperidinyl carbaldehyde (4) $\left(62 \%\right.$ yield) ${ }^{[4]}$. In entry (ii) ethyl isonepecotate (5) (commercial) was reduced to the 4-piperidylmethanol (6) in the presence of $\mathrm{LiAlH}_{4}$ in anhydrous THF $(90 \% \text { yield })^{[5]}$. The next step (entry iii) the synthesis of compound 7 was achieved by a reductive amination between the aldehyde 4 and piperidine derivative 6 in sodium triacetoxyborohydride $\left(\mathrm{NaBH}(\mathrm{OAc})_{3}\right)$ and 1,2 dichloroethane $(65 \% \text { yield })^{[6]}$. After that, the chloride atom of 7 was replaced by azide using $\mathrm{NaN}_{3}$ in DMF, which gave the key intermediate (4-piperidin-1-yl)[(4-azidequinolin-2-yl)-methyl] methyl alcohol (82\% yield) (8) (Scheme 1) ${ }^{[7]}$.

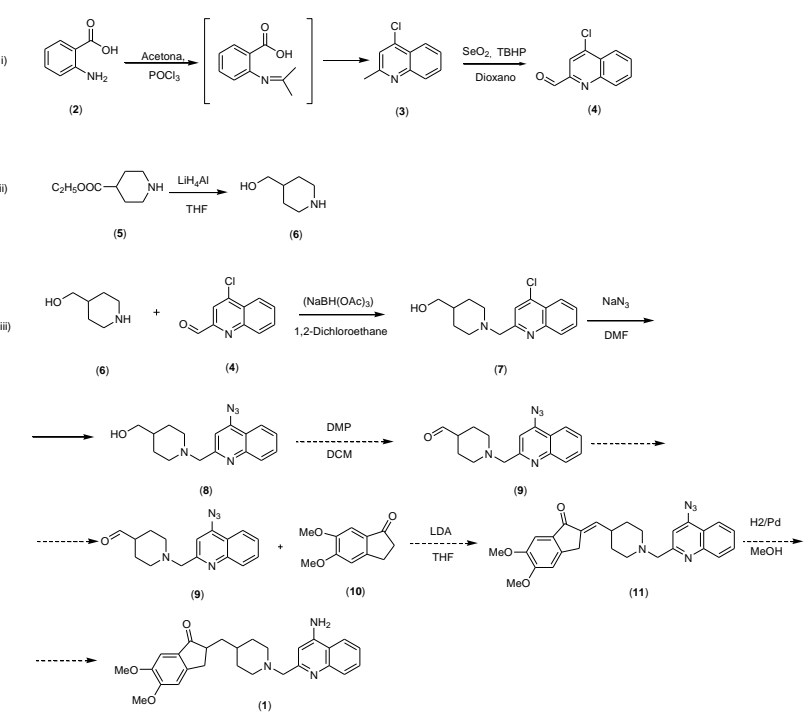

Scheme 1. Synthesis of the intermediate (4-piperidin-1yl)-[(4-azidequinolin-2-yl)-methyl] methyl alcohol (8) of a total synthesis of a potencial AchE inhibitor (1).

\section{CONCLUSION}

We have performed the preparation of the key intermediate 4-piperidin-1yl-[(4-azidequinolin-2-yl) methyl] methyl alcohol (8) of the total synthesis of a potencial AchE inhibitor (1). The next steps involves the condensation between the aldehyde derivative (9), obtained from oxidation of (8), with commercial 5,6 dimethoxy-1-indanone (10). The double bond formed of $\mathbf{1 1}$ will be reduced in parallel to the azide function in one pot reaction to achieve the desired compound $\mathbf{1}$, as shown before.

\section{ACKNOWLEDGEMENTS}

University of São Paulo, Faculty of Pharmaceutical Sciences of Ribeirão Preto, and Fapesp for the Financial support.

\section{REFERENCES}

[1] Rev.Bras.Psiquiatr. vol.21, s.2, Oct. 1999

[2] Journal of Molecular Graphics and Modelling v. 25, p. 169175, 2006.

[3] Bioorg. Med. Chem.,18. p. 5995-6005, 2010.

[4] Heterocycles v.60, n.4, p.953-957.

[5] Eur. J.Org. Chem, p.4277-4295, 2008.

[6] J.Org.Chem.v.61, p. 3849-3862, 1996.

[7] Química nova, v.29, n.3, p.444-51, 2006. 